\title{
Otimização do processo de nitrificação com o uso de conchas de ostras como material suporte em reatores aeróbios com biomassa fixa
}

\author{
Optimization of the nitrification process using oyster shells as a support \\ material in fixed biomass aerobic reactors
}

\begin{abstract}
Maria Elisa Magri
Engenheira Sanitarista e Ambiental pela Universidade Federal de Santa Catarina (UFSC). Mestre e Doutora em Engenharia Ambiental pela UFSC. Pesquisadora de Pós-doutorado pelo Programa de Pós-graduação em Biotecnologia e Biociências da UFSC - Florianópolis (SC), Brasil.
\end{abstract}

\section{Joceli Gorrezen Zaguini}

Formada em Ciências Contábeis pela Universidade do Vale do Itajaí (Univali). Técnica Ambiental pelo Centro Educacional Professor Padre Quirino (POSITEC). Bolsista de Apoio Técnico - CNPq - UFSC - Florianópolis (SC), Brasil.

\section{Sandra Regina Alexandre Ramos}

Engenheira Sanitarista e Ambiental pela UFSC. Mestranda em Engenharia Ambiental pelo PPGEA da UFSC. Bolsista CNPq - Florianópolis (SC), Brasil.

\section{Luiz Sérgio Philippi}

Engenheiro Civil pela UFSC. Doutor em Saneamento Ambiental pela Université de Montpellier I (França) e Professor Voluntário do Departamento de Engenharia Sanitária e Ambiental da UFSC - Florianópolis (SC), Brasil.

\section{Resumo}

A preservação dos mananciais de água traz como ponto de atuação primordial o tratamento dos esgotos sanitários a nível terciário. A partir daí destaca-se a necessidade de otimizar os sistemas de remoção de nutrientes, buscando-se processos mais estáveis, economicamente viáveis e ambientalmente sustentáveis. O objetivo desta pesquisa foi avaliar conchas de ostras como material de preenchimento em um biofiltro aerado submerso, assumindo-se a hipótese de que as mesmas podem interagir com a fase líquida do reator, fornecendo alcalinidade necessária à estabilidade do processo de nitrificação autotrófica. Uma série de condições operacionais foi avaliada visando à nitrificação; portanto, foi possível concluir que, no biofiltro aerado submerso com conchas de ostras, podem ser aplicadas taxas hidráulicas $>5,2 \mathrm{~m}^{3} \cdot \mathrm{m}^{-2} \cdot \mathrm{d}^{-1}$ e tempo de detenção hidráulico $<7,5$ horas, desde que a relação carbono: nitrogênio seja mantida abaixo de quatro. As conchas de ostras mantiveram o sistema tamponado $(\mathrm{pH}=7,5 \pm 0,3)$, mesmo com uma intensa atividade nitrificante no reator (100\%).

Palavras-chave: otimização; esgoto sanitário; biofiltro aerado submerso; nitrificação; conchas de ostras.

\section{Abstract}

One of the main key actions for water resources preservation is to promote wastewater treatment in a tertiary level. From this point, it can be highlighted the demands for optimizing the processes for nutrients removal aiming more stable processes, which are economically viable and environmentally sustainable. The aim of this research was to evaluate oyster shells as support material in an aerated submerged biofilter, having as main hypothesis the fact that they can interact with the liquid phase of the reactor, providing the necessary alkalinity to stabilize the autotrophic nitrification. The reactor studied was submitted to several operational conditions and could be concluded that, in the aerated submerged biofilter with oyster shells, hydraulic loadings can be $>5.2 \mathrm{~m}^{3} \cdot \mathrm{m}^{-2} . \mathrm{d}^{-1}$ and a hydraulic retention time $<7.5$ hours can be applied, since that the relation carbon: nitrogen is maintained under four. The oyster shells kept the system buffered $(\mathrm{pH}=7.5 \pm 0.3)$, even with a high nitrifying activity in the reactor $(100 \%)$.

Keywords: optimization; wastewater; aerated submerged biofilter; nitrification; oyster shells. 


\section{Introdução}

A escassez de água é um dos maiores problemas sanitário-ambientais, que ocorre como consequência do uso insustentável de recursos naturais e do crescimento populacional e econômico, cujos impactos tendem a ser cada vez mais graves. A preservação dos mananciais de água deve ter como ponto de atuação primordial o tratamento dos esgotos sanitários a nível terciário. A partir daí destaca-se a necessidade de otimizar os sistemas para remoção de nutrientes, buscando-se processos mais estáveis, economicamente viáveis e ambientalmente sustentáveis. Aliado à necessidade de preservação dos mananciais, o aumento da demanda pela redução de emissões de nitrogênio como um dos gases do efeito estufa intensifica a importância dos processos de nitrificação otimizados em uma base mais estável e eficiente (ALMSTRAND et al., 2011).

Vários são os fatores que afetam negativamente o processo de nitrificação autotrófica: elevadas cargas orgânicas aplicadas, curtos tempos de detenção hidráulica (TDH) e celular, baixas temperaturas, valores de $\mathrm{pH}$ extremos e baixas concentrações de oxigênio dissolvido (OD), os quais são mais rotineiros em estações de tratamento de esgotos domésticos. Fatores mais específicos também podem ser citados, tais como: deficiências de alguns nutrientes essenciais, presença de compostos tóxicos como solventes orgânicos, aminas, taninos, compostos fenólicos, álcoois, cianetos, éteres, carbamatos e benzeno, além de certos metais e das formas de nitrogênio em amônia livre $\left(\mathrm{NH}_{3}\right)$ e ácido nitroso não ionizado $\left(\mathrm{HNO}_{2}\right)$.

O processo de nitrificação em seu primeiro estágio produz ácidos (íons de hidrogênio), o que pode provocar uma diminuição do pH se a alcalinidade não for suficiente para proporcionar o tamponamento do sistema.

Gujer (2011) relatou os efeitos da baixa alcalinidade na nitrificação. A máxima atividade das bactérias oxidantes de amônia se mostrou afetada pelos efeitos do pH no interior de flocos biológicos ou biofilme devido à limitação provocada no processo de difusão. Consequentemente, a máxima atividade das bactérias oxidantes de nitrito sofre efeitos indiretos da má nitritação. Hawkins et al. (2012) estudaram tais resultados em nível molecular. Os genes RNA ribossômico (rDNA) e tradutor (rRNAt) de Nitrobacter spp. (oxidantes de nitritos) foram quantificados em um reator em escala laboratorial durante períodos de base com alta atividade nitrificante e em estágios de inibição induzida pela diminuição do $\mathrm{pH}$. As atividades dos rRNAt e rDNA foram metricamente diminuídas e refletidas nas mudanças da oxidação de nitritos.

O pH ótimo para bactérias nitrificantes está entre 7,5 e 8,5, sendo que naqueles abaixo de 6 o processo de nitrificação tende a cessar (EPA, 2003). Segundo Metcalf e Eddy (2003), as taxas de nitrificação declinam a partir do valor de $\mathrm{pH}=6,8$, sendo que, em valores próximos a 5,8 e 6,0 as mesmas podem ser reduzidas de 10 a $20 \%$ da taxa em $\mathrm{pH}=7,0$.
As bactérias nitrificantes podem aclimatar-se em reatores com valores de $\mathrm{pH}$ levemente mais ácidos; no entanto, levam mais tempo para adaptação e eventualmente podem ocorrer ciclos aonde predominem altas taxas de nitrificação e baixas taxas de remoção da demanda bioquímica de oxigênio (DBO) e vice-versa (Gray, 2004).

Para oxidação de 1 mol de amônia (18 g) a nitrato, aproximadamente dois moles de $\mathrm{H}^{+}$são gerados. No sistema de tamponamento carbonato/gás carbônico cada 2 moles de $\mathrm{H}^{+}$"consomem" 1 mol de alcalinidade na forma de carbonato de cálcio (100 g), como visto na Equação 1. Portanto, cada $1 \mathrm{~mol}$ de amônia oxidada (18 g) promove o "consumo" de $1 \mathrm{~mol}$ de carbonato (100 g).

$2 \mathrm{H}^{+}+\mathrm{CaCO}_{3} \rightarrow \mathrm{Ca}(\mathrm{OH})+2 \mathrm{CO}_{2}+\mathrm{H}^{+}$

Uma prática adotada em estações de tratamento de esgotos é a dosagem de $\mathrm{NaOH}$ ou $\mathrm{Ca}(\mathrm{OH})_{2}$, na tentativa de reduzir o problema de diminuição do pH em função do consumo de alcalinidade (MODIN et al., 2011).

Nos reatores com biomassa fixa, em alternativa à adição de produtos químicos, surge a avaliação de novos materiais de preenchimento e adesão de biofilme, os quais possam suprir o sistema com a alcalinidade necessária à estabilidade do processo.

Qiu et al. (2010) avaliaram a eficiência de três filtros biológicos aerados utilizando como materiais de preenchimento a cerâmica, a zeólita e um à base de carbonato. Morgan-Sagastume e Noyola (2008) testaram a escória vulcânica. Han et al. (2009) operaram um biofiltro aerado com um material suporte fabricado especificamente para este fim (escala somente exploratória), composto por lodo de esgoto desaguado mais argila e cinza leve. Yu et al. (2008) utilizaram grãos de escória de alto forno. Todos os autores citados tiveram bons resultados no tamponamento de seus reatores, promovendo uma nitrificação mais estável.

Ressalta-se, no entanto, que todos os materiais que interagem com o meio líquido fornecendo alcalinidade caracterizam-se como não inertes, podendo assim sofrer um processo de degradação dentro dos reatores.

No intuito de suprimir parte das demandas descritas, este trabalho teve como objetivo a avaliação do processo de nitrificação autotrófica em um biofiltro aerado submerso (BAS) com conchas de ostras como material de preenchimento ou suporte. As conchas de ostras foram estudadas, pois assume-se a hipótese de que as mesmas sendo formadas primordialmente por carbonato de cálcio podem interagir com a fase líquida do reator, fornecendo alcalinidade ao sistema e promovendo um tamponamento natural, necessário ao processo de nitrificação. O biofiltro foi avaliado com relação à eficiência no processo, sendo as conchas de ostras analisadas especificamente quanto ao potencial de tamponamento do reator e à sua degradação em consequência de tal interação. Esta última questão é importante para a validação do uso das conchas de ostras como meio suporte 
para reatores biológicos, pois, sendo um material não inerte, podem variar suas características ao longo do tempo, modificando sua eficiência na função que lhe foi atribuída.

\section{Metodologia}

\section{Descrição da unidade experimental}

A unidade experimental foi composta por um decanto-digestor para tratamento primário dos esgotos e um BAS preenchido com conchas de ostras para tratamento secundário e nitrificação. O esgoto que alimentava o sistema era bombeado da rede pública. $\mathrm{O}$ biofiltro possuía fluxo contínuo ascendente, com volume útil de 200 L e 40 L de material suporte.

O período de operação do sistema que gerou os dados apresentados neste trabalho foi de 300 dias. A operação foi dividida em duas fases com 150 dias cada, nas quais foram variados os TDH no reator, as taxas hidráulicas aplicadas e as relações de carbono: nitrogênio (DQO:N-NH${ }_{4}^{+}$). A Tabela 1 apresenta os parâmetros operacionais que caracterizaram as fases do sistema, bem como as principais características do biofiltro.

Observa-se que durante toda a operação não foi realizado descarte de lodo no biofiltro, visando à mínima interferência no processo de nitrificação.

Os pontos amostrados para avaliar a eficiência foram: afluente (A) e efluente (E) ao BAS, ABAS e EBAS, respectivamente. Os parâmetros físico-químicos avaliados apresentados neste trabalho foram: $\mathrm{pH}$, alcalinidade total, sólidos suspensos totais e série nitrogenada inorgânica. As análises foram realizadas segundo recomendações do Standard Methods for Examination of Water and Wastewater (APHA, 1998), com exceção do nitrogênio nitrato, que foi realizado seguindo a metodologia descrita por Vogel (1981).

Para avaliação das interações entre o material suporte e a fase líquida do biofiltro foram realizadas análises para determinação do desgaste das conchas de ostras em função do "consumo" de carbonato de cálcio pelo processo de nitrificação. As análises realizadas foram de perda de massa e perda de massa específica por descarbonatação.

Para realização destas, três coletores foram instalados dentro do biofiltro para coleta de conchas em três profundidades diferentes, sendo do fundo do reator até 0,4 m - coletor altura 3 (H3); de 0,4 a 0,8 m - altura 2 (H2); e de 0,8 a 1,2 m - altura $1(\mathrm{H} 1)$.

No início do experimento cada um dos três coletores foi preenchido com 14 conchas, as quais foram lavadas com água corrente e secas em estufa a $105^{\circ} \mathrm{C}$ por 24 horas. Ao final dos 300 dias de operação, os mesmos foram esvaziados e as conchas, analisadas novamente. Primeiramente, as conchas foram lavadas com água corrente para a remoção do biofilme e, em seguida, submetidas ao procedimento inicial de secagem em estufa. A perda de massa foi estimada pela diferença entre os respectivos pesos ao início e ao fim do experimento.
Tabela 1 - Parâmetros operacionais que caracterizaram as Fases 1 e 2 de operação do biofiltro aerado submerso, bem como suas principais dimensões.

\begin{tabular}{|c|c|c|}
\hline Parâmetros operacionais/dimensões do BAS & Fase 1 & Fase 2 \\
\hline Volume útil (L) & 200 & 200 \\
\hline Altura útil (m) & 1,35 & 1,35 \\
\hline Área superficial de fundo $\left(\mathrm{m}^{2}\right)$ & 0,005 & 0,005 \\
\hline Vazão - Q (L.h-1) & 13,2 & 26,4 \\
\hline Tempo de detenção hidráulico - TDH (h) & 15 & 7,5 \\
\hline Oxigênio dissolvido - OD (mg. $\left.\mathrm{L}^{-1}\right)$ & $3,0-6,0$ & $3,0-6,0$ \\
\hline $\begin{array}{l}\text { Carga orgânica volumétrica - COV } \\
\left(\mathrm{gDQO} \cdot \mathrm{m}^{-3} \cdot \mathrm{dia}^{-1}\right)^{\star}\end{array}$ & 370 & 370 \\
\hline Taxa de aplicação superficial - TAS $\left(m \cdot h^{-1}\right)$ & 2,6 & 5,3 \\
\hline Relação C:N (DQO:N-NH ${ }_{4}^{+}$) & 5,0 & 3,7 \\
\hline
\end{tabular}

*No cálculo da COV foi utilizada a concentração da demanda química de oxigênio (DQO) média de entrada no biofiltro aerado submerso (BAS) de $232 \mathrm{mg}^{\mathrm{L}^{-1}}$, na Fase 1, e 116 mg. $\mathrm{L}^{-1}$, na Fase 2 .

Após a análise de perda de massa as conchas foram submetidas à perda de massa por descarbonatação. A descarbonatação do carbonato de cálcio é uma reação exotérmica e ocorre na temperatura de $750^{\circ} \mathrm{C}$. Com a descarbonatação, o $\mathrm{CaCO}_{3}$ perde o carbono inorgânico constituinte na forma de gás carbônico, restando somente o metal formador óxido de cálcio.

Todas as amostras após secas em estufa foram pesadas e levadas a um forno tipo mufla a $750^{\circ} \mathrm{C}$ por uma hora. A perda de massa das cascas por descarbonatação foi estimada, então, pela diferença entre os pesos iniciais e finais (antes e após muflagem). O mesmo procedimento de descarbonatação foi realizado com conchas não utilizadas como material de preenchimento, a fim de comparar o percentual de descarbonatação.

\section{Avaliação dos dados}

Para avaliação do sistema foram utilizados os dados coletados durante os 300 dias de operação, que estão apresentados em tabelas e gráficos temporais de dispersão. Foi realizada análise estatística de variância (ANOVA) - one-way para avaliação das diferenças entre os dados coletados nas duas fases operacionais. Antes de sua realização, a distribuição dos dados foi avaliada, sendo que aqueles que não apresentaram distribuição normal foram transformados logaritmicamente (quando $\mathrm{x}=0, \mathrm{x}^{\prime}=\log _{10}(\mathrm{x}+1)$ ).

\section{Resultados e discussão}

\section{Nitrificação no biofiltro aerado submerso - Fase 1}

A Figura 1 apresenta o comportamento dos compostos nitrogenados inorgânicos no BAS durante a Fase 1.

O BAS apresentou 90\% de remoção média de nitrogênio amoniacal, com concentrações efluentes média, máxima e mínima de 4,6, 41,3 e 0,4 mg. $\mathrm{L}^{-1}$, respectivamente. Do percentual de $90 \%$ da 


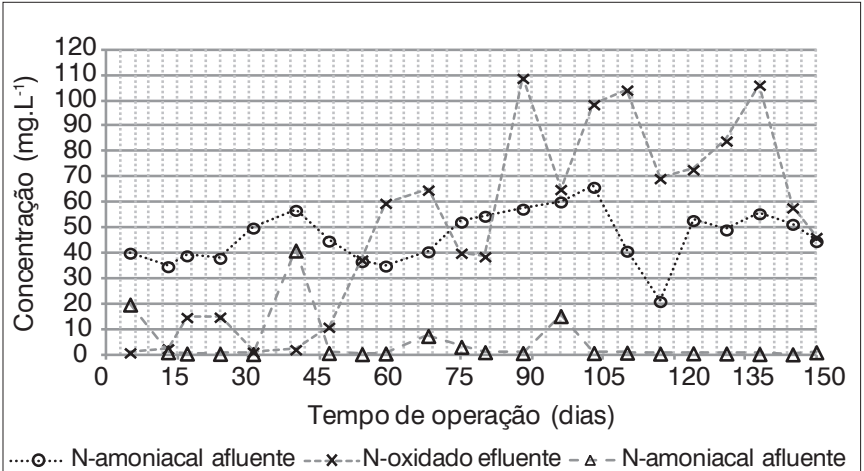

Figura 1 - Série temporal de concentrações dos compostos nitrogenados inorgânicos no biofiltro aerado submerso, Fase 1.

amônia removida, pode-se considerar que 100\% foram nitrificados, pois a concentração efluente média de nitrogênio oxidado (nitrato $\left.=50,0 \mathrm{mg} . \mathrm{L}^{-1}\right)$ foi superior àquela afluente de nitrogênio oxidável (amônia=46,6 mg. $\mathrm{L}^{-1}$ ).

Durante os 150 dias de operação, o processo de nitrificação ocorreu de forma estável, com exceção de um pico de liberação de amônia entre os dias 30 e 45 , em que a remoção foi de $28 \%$. Somente $4 \%$ desta amônia removida foi transformada em nitratos e o restante provavelmente foi incorporado à biomassa para síntese celular.

O balanço de massa do nitrogênio inorgânico no reator realizado por meio da Equação 2, com base nos resultados das análises laboratoriais, mostra que:

$\mathrm{P}=\mathrm{CE}_{\mathrm{NH} 4}+\mathrm{CE}_{\mathrm{NO} 2}+\mathrm{CE}_{\mathrm{NO} 3}-\left(\mathrm{CS}_{\mathrm{NH}_{4}}+\mathrm{CS}_{\mathrm{NO} 2}+\mathrm{CS}_{\mathrm{NO} 3}\right)$

perdas: - $6.9 \mathrm{mg} \cdot \mathrm{L}^{-1}$;

onde:

$\mathrm{CE}_{\mathrm{NH} 4}$ : concentração de amônia na entrada do reator (mg. $\left.\mathrm{L}^{-1}\right)$;

$\mathrm{CE}_{\mathrm{NO} 2}$ : concentração de nitrito na entrada do reator $\left(\mathrm{mg} \cdot \mathrm{L}^{-1}\right)$;

$\mathrm{CE}_{\mathrm{NO} 3}$ : concentração de nitrato na entrada do reator $\left(\mathrm{mg} \cdot \mathrm{L}^{-1}\right)$;

$\mathrm{CS}_{\mathrm{NH} 4}$ : concentração de amônia na saída do reator $\left(\mathrm{mg} . \mathrm{L}^{-1}\right)$;

$\mathrm{CS}_{\mathrm{NO} 2}$ : concentração de nitrito na saída do reator (mg. $\left.\mathrm{L}^{-1}\right)$;

$\mathrm{CS}_{\mathrm{NO} 3}$ : concentração de nitrato na saída do reator $\left(\mathrm{mg} . \mathrm{L}^{-1}\right)$.

Interpretando-se o resultado da perda de $\mathrm{N}$-inorgânico, pode-se considerar que o decréscimo negativo de $6,9 \mathrm{mg}$. $\mathrm{L}^{-1}$ ocorreu principalmente em função da formação de nitratos no reator, que superou a concentração afluente de nitrogênio passível de ser oxidado.

O excesso de nitrato foi formado possivelmente a partir das frações de N-orgânico afluentes que foram transformadas em $\mathrm{N}$-amoniacal, e a partir deste, foi liberado no meio quando da ocorrência de morte celular.

No entanto, percebe-se que a formação de nitratos a partir do $50^{\circ}$ dia de operação ocorreu com a liberação de picos efluentes superiores às respectivas concentrações de $\mathrm{N}$-amoniacal afluentes, coincidindo, consequentemente, com os picos de perda de N-inorgânico negativos. Esse processo pode ser relacionado com o desprendimento de biofilme do reator, quantificado por meio da concentração de sólidos em suspensão (SS) efluente. A Figura 2 apresenta tal relação por meio da série temporal das perdas de nitrogênio inorgânico, relacionada com as concentrações de sólidos suspensos no EBAS.

Analisando-se primeiramente a série temporal das perdas apresentada na Figura 2, observou-se que até o dia 54 as perdas de N-inorgânico foram positivas, ou seja, as concentrações efluentes de $\mathrm{N}_{-} \mathrm{NH}_{4}{ }^{+}$mais $\mathrm{N}^{-\mathrm{NO}_{2}}{ }_{2}^{-}$e N-NO${ }_{3}^{-}$foram inferiores às afluentes. Esse fato deve-se ao tempo de operação do reator, pois, no período dos primeiros 50 dias, os processos predominantes foram as reações de síntese para formar biomassa no sistema e, consequentemente, uma maior quantidade de nutrientes foi utilizada não nos processos oxidativos, mas na síntese celular. Este fenômeno foi também descrito por Gálvez et al. (2003). Assim, com o fim do período de formação e estabilização de biomassa no reator as perdas passaram a ser negativas.

Os picos de perdas negativos iniciados a partir do dia 54 de operação foram coincidentes com aqueles de desprendimento de biomassa (SS) do BAS. Isso pode ser entendido como resultado de dois fenômenos. O primeiro é o aumento da concentração de N-amoniacal do meio proveniente da amonificação do nitrogênio das células que formam o biofilme que foi desprendido. Este $\mathrm{N}$-amoniacal entra no ciclo da nitrificação estabelecida no reator sendo transformado em nitrato. O segundo fenômeno diz respeito à elevação da transferência de oxigênio para o biofilme autotrófico. De acordo com Elenter et al. (2007), em reatores com presença concomitante de bactérias heterotróficas e autotróficas, a formação do biofilme ocorre normalmente com o estabelecimento do filme autotrófico nas camadas mais internas e do filme heterotrófico sobre as mesmas, portanto, a taxa de nitrificação passa a ter como fator limitante a transferência de oxigênio. Com o desprendimento de biofilme, sendo este das camadas mais externas, a elevação das taxas de transferência de oxigênio para o biofilme autotrófico eleva as taxas de nitrificação, aumentando a concentração de nitratos no efluente.

Pode-se concluir, então, que o desprendimento natural de biofilme ocorrido no BAS foi favorável para elevação da taxa de nitrificação. Observa-se que este é um dos objetivos da realização de retrolavagens e descartes de lodo em reatores com biomassa aderida. No entanto, o desprendimento forçado de biofilme quando não é bem controlado pode causar o arraste das bactérias nitrificantes, prejudicando o funcionamento do sistema.

\section{Nitrificação no biofiltro aerado submerso - Fase 2}

A Figura 3 apresenta o comportamento dos compostos nitrogenados inorgânicos no BAS durante a Fase 2.

O BAS durante a Fase 2 obteve uma remoção média de N-amoniacal de 98\%, com concentrações efluentes média, máxima e mínima de 
0,7, 1,3 e 0,2 mg. $\mathrm{L}^{-1}$, respectivamente. Durante todo o período a remoção de amônia foi estável. Do percentual de 98\% de amônia removida, pode-se considerar que $100 \%$ sofreram o processo de nitrificação completa, pois a concentração efluente de nitratos $\left(51,8 \mathrm{mg} . \mathrm{L}^{-1}\right)$ foi mais elevada do que a afluente de amônia (32,2 mg. $\left.\mathrm{L}^{-1}\right)$.

$\mathrm{Na}$ Fase 2, durante quase todo o período, as perdas de N-inorgânico foram negativas (Figura 4), com uma média de -19,6 mg.L-1 (Equação 1), indicando que a média de nitrogênio oxidado efluente foi maior do que o nitrogênio oxidável (amônia) afluente.

Durante os 150 dias de operação da Fase 2 as perdas foram negativas, com exceção do período entre os dias 200 e 213, nos quais foram positivas. Este período foi coincidente com um evento de elevado desprendimento de biomassa, em que a concentração de SS efluente atingiu $243 \mathrm{mg} . \mathrm{L}^{-1}$. Diferentemente das consequências relatadas anteriormente, nas quais o desprendimento de biofilme foi associado com o aumento da formação de nitratos e com os picos de perdas negativas, como ocorrido também no dia 192 de amostragem, o desprendimento de biofilme nesta ocasião foi excessivo ocasionando perda de biomassa autotrófica e heterotrófica. Em função disso, o nitrogênio foi teoricamente mais utilizado nas reações de síntese e menos nas de oxidação, da mesma forma como ocorreu no 'start up' do sistema.

\section{Avaliação comparativa dos dados e}

\section{análise de variância entre as Fases 1 e 2}

Os resultados obtidos na remoção de nitrogênio e nitrificação no BAS, nas Fases 1 e 2, bem como as principais características de cada fase operacional estão resumidos na Tabela 2.

Foi realizada Anova a fim de verificar se as diferenças no processo de nitrificação entre as Fases 1 e 2, apresentadas por meio dos dados das análises físico-químicas, foram significativas. Observa-se que os

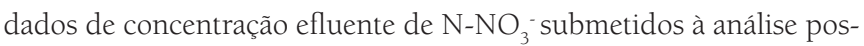
suíram uma distribuição estatística normal, ao passo que aqueles de $\mathrm{N}-\mathrm{NH}_{4}{ }^{+}$tiveram que ser normalizados.

Foram encontrados valores de p>0,05, portanto há diferença entre as séries de dados. Assim, pode-se afirmar que os dados médios obtidos são diferentes: nas Fases 1 e 2 do BAS em termos de remoção de $\mathrm{N}_{-} \mathrm{NH}_{4}{ }^{+}(\mathrm{p}=0,080)$ e formação de $\mathrm{N}^{-\mathrm{NO}_{3}}{ }^{-}(\mathrm{p}=0,754)$.

O BAS foi mais eficiente com $98 \%$ de remoção de $\mathrm{N}_{-} \mathrm{NH}_{4}{ }^{+}$na Fase 2 , sendo que na primeira a eficiência média alcançada foi de $90 \%$.

Quase todos os parâmetros operacionais foram teoricamente mais limitantes na Fase 2. No entanto, as melhores eficiências de remoção de nitrogênio amoniacal foram alcançadas em tal fase. A carga

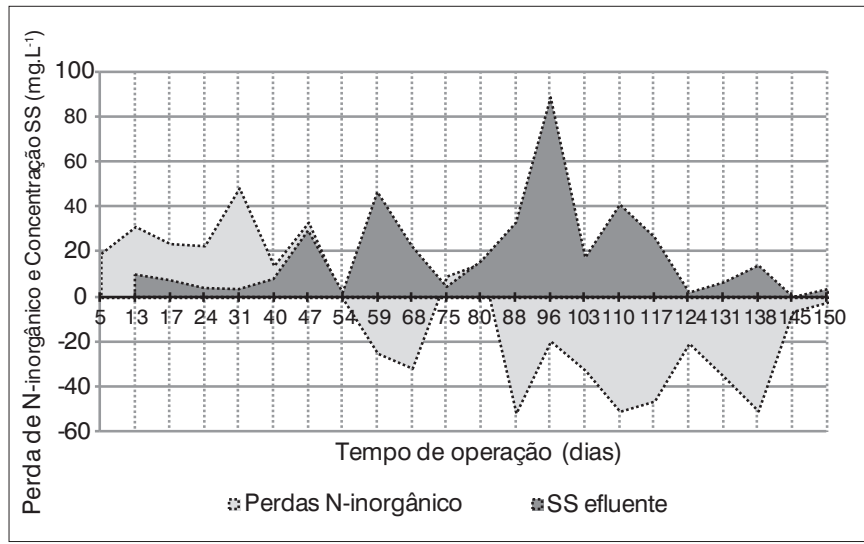

Figura 2 - Série temporal das perdas de N-inorgânico e concentrações efluentes de sólidos suspensos (SS) no biofiltro aerado submerso, Fase 1.

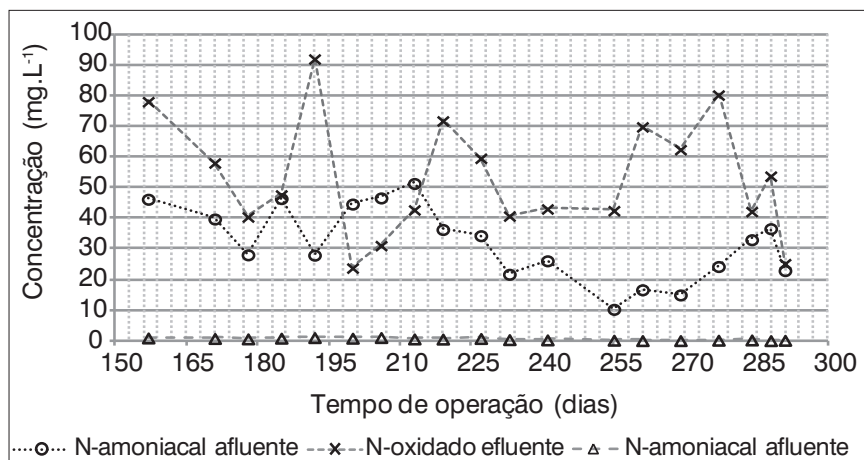

Figura 3 - Série temporal de concentrações dos compostos nitrogenados inorgânicos no biofiltro aerado submerso, Fase 2.

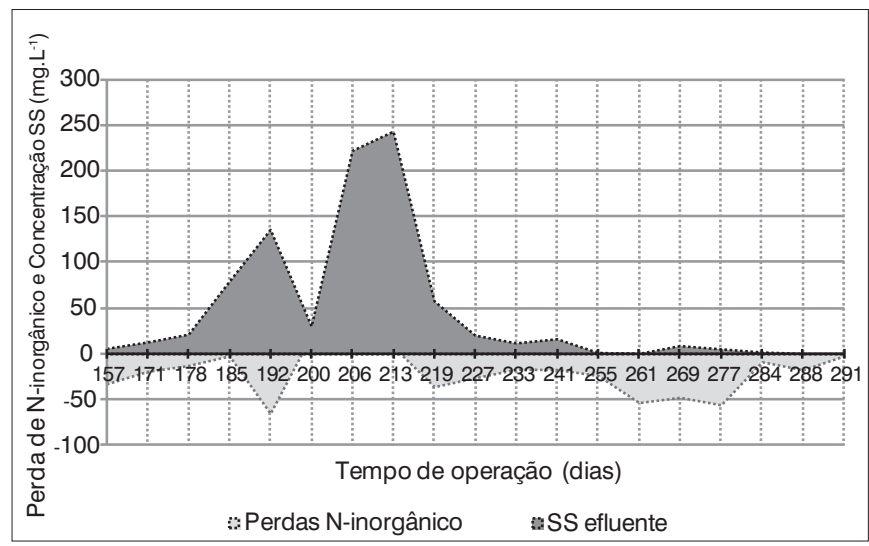

Figura 4 - Série temporal das perdas de N-inorgânico e concentrações efluentes de sólidos suspensos (SS) no biofiltro aerado submerso, Fase 2.

Tabela 2 - Resumo dos dados obtidos na remoção de nitrogênio e nitrificação no biofiltro e principais características operacionais das Fases 1 e 2.

\begin{tabular}{|c|c|c|c|c|c|c|c|c|c|}
\hline Fase & TDH (h) & $\mathrm{C}: \mathrm{N}$ & $\begin{array}{c}\text { TAS } \\
\left(\mathrm{m}^{3} \cdot \mathrm{m}^{-2} \cdot \mathrm{d}^{-1}\right)\end{array}$ & $\begin{array}{c}\mathrm{CV} \\
\left(\mathrm{gN}-\mathrm{NH}_{4}^{+} \cdot \mathrm{m}^{-3} \cdot \mathrm{d}^{-1}\right)\end{array}$ & $\begin{array}{l}\mathrm{N}-\mathrm{NH}_{4}{ }^{+} \text {afluente } \\
\left(\mathrm{mg} \cdot \mathrm{L}^{-1}\right)\end{array}$ & $\begin{array}{l}\mathrm{N}-\mathrm{NH}_{4}{ }^{+} \text {efluente } \\
\left(\mathrm{mg}^{\left.-\mathrm{L}^{-1}\right)}\right.\end{array}$ & $\begin{array}{l}\mathrm{N}-\mathrm{NO}_{3}^{-} \text {- efluente } \\
\left(\mathrm{mg}^{\left.-\mathrm{L}^{-1}\right)}\right.\end{array}$ & $\begin{array}{c}\text { Remoção } \\
\mathrm{N}-\mathrm{NH}_{4}{ }^{+}(\%)\end{array}$ & Nitrificação (\%) \\
\hline 1 & 15 & 5,0 & 2,6 & 74 & $46,6 \pm 10,5$ & $4,6 \pm 9,6$ & $50,0 \pm 36,8$ & 90 & 100 \\
\hline 2 & 7,5 & 3,7 & 5,2 & 102 & $32,2 \pm 11,9$ & $0,7 \pm 0,4$ & $53,0 \pm 19,1$ & 98 & 100 \\
\hline
\end{tabular}

CV: carga volumétrica de $\mathrm{N}^{-\mathrm{NH}_{4}^{+}}$; TAS: taxa de aplicação superficial; C:N: carbono e nitrogênio; TDH: tempo de detenção hidráulica. 
volumétrica de amônia aplicada e as taxas hidráulicas foram mais elevadas e o TDH foi menor. Os principais fatores que foram identificados como mais favoráveis à nitrificação na Fase 2 foram: a relação C:N (DQO:N-NH ${ }_{4}^{+}$, menor na Fase $2(3,7)$ do que na $1(5,0)$, e o fato de que a biomassa do reator estava mais adaptada na segunda fase. Observa-se que as concentrações de OD foram mantidas iguais nas duas etapas, sendo consideradas favoráveis ao processo de nitrificação.

Em resumo, concluiu-se que podem ser aplicadas maiores taxas hidráulicas e cargas volumétricas e menores TDHs no reator com conchas de ostras, desde que a relação C:N seja diminuída, sendo que a maior estabilidade da biomassa tende a favorecer o processo de nitrificação. Ressaltase a importância do pré-tratamento eficiente ao reator terciário para que quantidades suficientes de carga orgânica sejam previamente removidas, promovendo a prevalência das bactérias autotróficas sobre as heterotróficas no mesmo.

Vale ressaltar ainda que, apesar da maior eficiência de remoção de N-amoniacal na Fase 2, as duas fases operacionais apresentaram resultados considerados satisfatórios. Destaca-se a estabilidade do reator, proporcionada pelo tamponamento natural promovido pelas conchas de ostras no sistema, mantendo as condições de neutralidade do meio em termos de $\mathrm{pH}$ e alcalinidade (apresentado mais detalhadamente nos itens subsequentes).

Morgan-Sagastume e Noyola (2008) operaram um BAS com características e resultados semelhantes aos apresentados neste trabalho. O TDH médio foi de seis horas e o meio suporte não inerte à escória vulcânica. As cargas volumétricas de amônia aplicadas foram em média $60 \pm 20 \mathrm{~g} \mathrm{~N}^{-N_{4}}{ }_{4}^{+} \cdot \mathrm{m}^{-3} \cdot \mathrm{d}^{-1}$, sendo alcançadas eficiências de até $90 \%$ de remoção quando aquelas orgânicas em termos de DQO foram inferiores a $1.700 \mathrm{~g}$ DQO. $\mathrm{m}^{-3} \cdot \mathrm{d}^{-1}$. O sistema foi operado sem retrolavagens, como o sistema aqui estudado, pois, do ponto de vista dos autores, em reatores que visem à nitrificação e possuam um leito filtrante com um elevado número de vazios, deve-se proceder de forma que as bactérias nitrificantes possuam estabilidade, sendo a adoção das unidades de tratamento complementares a melhor forma para eliminação dos SS em excesso.

Xie et al. (2004) realizaram um experimento em escala real para o tratamento dos esgotos de uma residência com sete pessoas e instalaram um BAS com 571 L e leito de espuma de poliestireno. Com a aplicação de

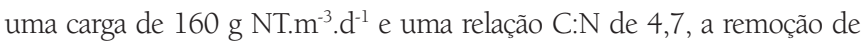
$\mathrm{N}$-amoniacal foi de $86 \%$.

Carvalho Júnior e Povinelli (2005) conduziram uma pesquisa com a operação de um sistema composto por um RAC (11.000 L) e BAS (760 L) de fluxo ascendente, preenchido também com espuma de poliuretano. Foi alcançada a remoção de 58\% de N-amoniacal no BAS, com uma COV e TDH respectivamente de 280 gDBO. $\mathrm{m}^{-3} \cdot \mathrm{d}^{-1}$ e 12 horas. Observa-se que no trabalho citado as retrolavagens do leito foram diminuídas para obter atividade nitrificante no reator, procedimento semelhante ao recomendado por Morgan-Sagastume e Noyola (2008) e ao adotado neste trabalho.

Qiu et al. (2010) avaliaram a eficiência de três filtros aerados utilizando como material de preenchimento cerâmica, zeólita e um à base de carbonato. Foi observado que até $50 \%$ da amônia pôde ser removida quando COV foi menor do que $6 \mathrm{~kg}$ DQO. $\mathrm{m}^{-3} \cdot \mathrm{d}^{-1}$. No entanto, somente 20 a 40\% quando a carga excedeu este valor. A carga de amônia limitante foi de $1,2 \mathrm{~kg} \cdot \mathrm{m}^{-3} \cdot \mathrm{d}^{-1}$, superior à estudada nesta pesquisa, o que deixa clara a possibilidade de aplicação de outras mais elevadas quando o processo de nitrificação é estável.

\section{Avaliação da capacidade de tamponamento das conchas de ostras no biofiltro}

A Tabela 3 apresenta os resultados dos parâmetros 'alcalinidade total' e 'potencial hidrogeniônico' nos afluentes e efluentes ao BAS nas Fases 1 e 2 de operação do sistema.

O biofiltro manteve uma ótima capacidade de tamponamento durante o período de operação do experimento, mesmo com uma intensa atividade nitrificante no reator. Esse fato deve-se ao material utilizado como meio suporte, ou seja, as conchas de ostras, que, além de realizarem a função de suporte para aderência de biofilme, atuaram no fornecimento de alcalinidade ao sistema.

O BAS durante a Fase 1 apresentou um pH médio de 7,5. Na Fase 2 o comportamento do $\mathrm{pH}$ no biofiltro foi semelhante à primeira, $\mathrm{com} \mathrm{pH}$ médio de 7,5.

Com relação ao comportamento da alcalinidade total, na Fase 1 as concentrações média, máxima e mínima efluentes ao BAS foram, respectivamente, 76,6, 238,8 e 44,6 mg. $\mathrm{L}^{-1}$.

Estequiometricamente, cada $1 \mathrm{~mol}$ de amônia oxidada (18.000 mg) promove o "consumo" de $1 \mathrm{~mol}$ de carbonato (100.000 mg), ou seja, a cada $1 \mathrm{mg}$ de amônia oxidada a nitrato, 5,56 mg de carbonato são "consumidos".

Se for considerado que, na Fase 1, foram formados em média

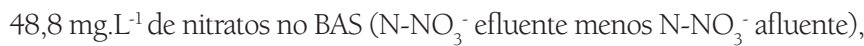
de acordo com a relação estequiométrica apresentada 271,3 mg..-1-1 de carbonato foram consumidos neste processo.

Se no afluente a alcalinidade média foi de 277,0 mg. $\mathrm{L}^{-1}$ e, desta 271,3 mg. L $^{-1}$ foram consumidos no processo de nitrificação, conclui-se simplificadamente que o efluente do reator deveria apresentar a alcalinidade igual a 5,7 mg.L-1 , todavia aquela efluente foi em média de 76,6 mg. $\mathrm{L}^{-1}$. Portanto, pode-se assumir que as conchas de ostras forneceram uma média de 70,9 mg. $\mathrm{L}^{-1}$ do carbonato de cálcio ao sistema.

Repetindo-se este mesmo raciocínio para os resultados na Fase 2, tem-se que as cascas de ostras forneceram 107,6 mg..-1 de carbonato de cálcio para o tamponamento do sistema frente às reações de oxidação com a liberação de íons $\mathrm{H}^{+}$.

Esse fato foi primordial para o ótimo resultado obtido na nitrificação dos efluentes, ressaltando-se que o fornecimento de alcalinidade ao sistema permitiu que o $\mathrm{pH}$ no reator se mantivesse estável com valores, na maior parte do tempo, entre 7 e 8 .

Outra questão importante que pode ser destacada foi a não formação de espuma no biofiltro, pois o efluente apresentou dureza proveniente do carbonato suficiente para evitar que isso ocorresse. 
Hoffmann et al. (2005) obtiveram bons resultados com a utilização das cascas de ostras para estabilizar processos aeróbios de tratamento de esgotos com baixa alcalinidade, mas no estudo em questão os autores utilizaram uma porção de conchas no interior do tanque de tratamento primário de seu sistema e somente os efluentes, com sua alcalinidade um pouco mais elevada, seguiam para o reator aeróbio.

Sengupta et al. (2006) escolheram as cascas de ostras como material de enchimento de um biorreator para desnitrificação autotrófica de esgotos domésticos, também com a finalidade de aumentar a alcalinidade do efluente.

Dos três materiais de enchimento estudados por Qiu et al. (2010), cerâmica, zeólita e um à base de carbonato, este foi relatado como o mais eficiente. Quando o afluente ao sistema estudado pelos autores foi menor do que 6,5 , o carbonato manteve o sistema tamponado mantendo a atividade nitrificante no reator em $80 \%$.

\section{Avaliação da perda de massa e \\ descarbonatação das conchas de ostras no biofiltro}

A Tabela 4 apresenta a massa total por concha de ostra inicial e final dos três coletores do biofiltro, bem como a perda de massa média por unidade.

As conchas de ostras do BAS perderam em média 1,4 g por unidade ou $6,3 \%$ de sua massa em percentual no período correspondente a 300 dias de utilização.

Observa-se que esses decréscimos ligeiramente superiores foram encontrados no fundo do reator (coletor na altura 3), diminuindo verticalmente no sentido do fluxo hidráulico (ascendente). As maiores perdas no fundo podem ser explicadas pelo maior turbilhonamento e atividade biológica nesta área, em função da maior disponibilidade de substrato.

Considerando-se que a perda de massa é linear ao logo do tempo, as conchas de ostras levariam em média 12 anos para serem totalmente "consumidas" no sistema estudado.

A perda de massa pôde ser percebida também visualmente nos reatores pela altura do leito filtrante, que apresentou uma redução de $9 \mathrm{~cm}$.

A descarbonatação percentual das conchas não utilizadas e daquelas ao final do experimento foi semelhante (respectivamente 3,6 e 3,5\%). Se durante a utilização como meio suporte as conchas de ostras perdessem somente quantidades de seu carbonato de cálcio, sendo os outros constituintes mantidos inalterados, o que ocorreria na análise de descarbonatação seria que as conchas ao final do experimento apresentariam uma perda menor de carbonato do que as não utilizadas, devido ao fato de possuírem menos carbonato de cálcio. No entanto, isto não ocorreu.
Pode-se concluir pelos resultados das análises apresentadas neste item que as conchas de ostras, quando utilizadas no reator, sofreram uma perda de massa. No entanto, isso foi uniforme, ou seja, partes proporcionais de todos os seus constituintes foram perdidas e não somente o carbonato de cálcio.

\section{Conclusões}

As condições operacionais da Fase 2 proporcionaram melhores eficiências na remoção do nitrogênio amoniacal no biofiltro. Nesta fase foram aplicadas as maiores taxas hidráulicas, os menores TDH e a menor relação $C: N$.

Destaca-se a necessidade da realização de um pré-tratamento eficiente para redução de carga orgânica na entrada do biofiltro e um pós-tratamento para remoção do excesso de SS. Pode-se estimar com os dados obtidos que o desgaste das conchas de ostras foi de 6,7\% por ano, sendo possível calcular o tempo de vida útil do material suporte no reator.

Por fim, os estudos apontaram que as conchas de ostras são um material robusto, com boa capacidade de fornecimento de alcalinidade ao sistema e aderência de biofilme. Uma questão importante que favorece o uso das conchas de ostras é a disponibilidade deste material no litoral do Brasil, principalmente na região Sul. Apesar das crescentes pesquisas sobre alternativas de reúso, atualmente as conchas são um passivo ambiental, dispensadas no ambiente como resíduos. Esse fator, aliado à eficiência satisfatória obtida com a utilização das mesmas no tratamento dos esgotos, são os pontos fortes que justificam a sua utilização. No entanto, é reconhecida a necessidade de continuação das pesquisas para avaliar este sistema a longo prazo, bem como o teste em condições mais limitantes de vazão e oxigenação.

Tabela 3 - Resultados da alcalinidade total e pH nos afluentes e efluentes do biofiltro aerado submerso (BAS) - Fases 1 e $2(n=22)$.

\begin{tabular}{lcccc} 
Fases & \multicolumn{2}{c}{$\begin{array}{c}\text { Alcalinidade total } \\
\left(\mathrm{mg} \mathrm{CaCO}_{3} \cdot \mathrm{L}^{-1}\right)\end{array}$} & \multicolumn{2}{c}{$\begin{array}{c}\text { Potencial } \\
\text { hidrogeniônico }\end{array}$} \\
\cline { 2 - 5 } & ABAS & EBAS & ABAS & EBAS \\
Média & 277,0 & 76,6 & 7,2 & 7,5 \\
Máximo & 377,4 & 238,8 & 7,7 & 8,1 \\
\hline Mínimo & 56,8 & 44,6 & 7,2 & 6,6 \\
\hline DP & 67,5 & 41,4 & 0,2 & 0,3 \\
\hline Média & 283,8 & 100,5 & 7,3 & 7,5 \\
Máximo & 690,2 & 187,2 & 7,7 & 8,1 \\
Mínimo & 159,0 & 65,6 & 6,5 & 6,4 \\
\hline DP & 144,8 & 39,6 & 0,3 & 0,3
\end{tabular}

DP: desvio padrão da média; $n$ : tamanho amostral.

Tabela 4 - Perda de massa por unidade de concha de ostra nos três coletores nas três alturas avaliadas $(n=14)$.

\begin{tabular}{|c|c|c|c|c|c|c|c|c|}
\hline \multirow{2}{*}{ Dados } & \multicolumn{2}{|c|}{ Coletor - H1 } & \multicolumn{2}{|c|}{ Coletor - H2 } & \multicolumn{2}{|c|}{ Coletor - H3 } & \multicolumn{2}{|c|}{ Média } \\
\hline & Inicial & Final & Inicial & Final & Inicial & Final & Inicial & Final \\
\hline Massa média por unidade (g) & 21,2 & 20,0 & 22,9 & 21,4 & 20,7 & 19,2 & 21,6 & 20,2 \\
\hline Perda de massa média (g) & \multicolumn{2}{|c|}{1,2} & \multicolumn{2}{|c|}{1,4} & \multicolumn{2}{|c|}{1,5} & \multicolumn{2}{|c|}{1,4} \\
\hline Perda de massa média (\%) & \multicolumn{2}{|c|}{5,6} & \multicolumn{2}{|c|}{6,3} & \multicolumn{2}{|c|}{7,0} & \multicolumn{2}{|c|}{6,3} \\
\hline
\end{tabular}




\section{Referências}

ALMSTRAND, R.; LYDMARK, P.; SÖRENSSON, F.; HERMANSSON, M. (2011) Nitrification potential and population dynamics of nitrifying bacterial biofilms in response to controlled shifts of ammonium concentrations in wastewater trickling filters. Bioresource Technology, v. 102, p. 7685-7691.

APHA - American Public Health Association. (1998) Standard methods for the examination of water and wastewater. 19. ed. Washington: APHA.

CARVALHO JÚNIOR, O.; POVINELLI, J. (2005) Biofiltro Aeróbio Submerso empregado no pós-tratamento do efluente de reator anaeróbio compartimentado. In: Congresso Brasileiro de Engenharia Sanitária e Ambiental, 23. Anais... Campo Grande: ABES. CD ROM, 11 p.

ELENTER, D.; MILFERSTEDT, K.; ZHANG, W.; HAUSNER, M.; MORGENROTH, E. (2007) Influence of fetachment on substrate removal and microbial ecology in a heterotrophic/ autotrophic biofilm. Water Research, v. 41, p. 4657-4671.

EPA - Environmental Protection Agency. (2003) Nutrient Reduction in Domestic Wastewater from Individual Residential Homes. Report. New Jersey, USA: NSF International, $102 \mathrm{p}$.

GUJER, W. (2011) Nitrification and me - A subjective review. Water research, v. 44, p. 1-19.

GÁLVEZ, J..M; GÓMEZ, M.A.; HONTORIA, E.; GONZÁLEZ-LÓPEZ, J. (2003) Influence of hydraulic loading and air flowrate on urban wastewater nitrogen removal with a submerged fixed-film reactor. Journal of Hazardous Materials, v. 101, p. 219-229.

GRAY, N.F. (2004) Biology of wastewater treatment. 2 ed. London: Imperial College Press, $1421 \mathrm{p}$.

HAN, S.; YUE, Q.; YUE, M.; GAO, B.; ZHAO, Y.; CHENG, W. (2009) Effect of sludge-fly ash ceramic particles (SFCP) on systhetic wastewater treatment in an $\mathrm{A} / \mathrm{O}$ combined biological aerated filter. Bioresource Technology, v. 100, p. 1149-1155

HAWKINS, S.; ROBINSON, K.; LAYTON, A.; SAYLER, G. (2012) Molecular indicators of Nitrobacter spp. population and growth activity during an induced inhibition event in a bench scale nitrification reactor. Water Research, doi:10.1016/j.watres.2011.12.053.

HOFFMANN, H.; COSTA, T.B.; WOLFF, D.B.; PLATZER, C.; COSTA, R.H.R. (2005) Uso de cascas de ostras para estabilização de processos aeróbios de tratamento de esgotos com baixa alcalinidade. In: Congresso Brasileiro de Engenharia Sanitária e Ambiental, 23. Anais... Campo Grande: ABES. CD ROM, 7 p.

METCALF \& EDDY. (2003) Wastewater engineering: treatment, disposal and reuse. 4 ed. New York, USA: McGraw-Hill, 1334 p.

MODIN, O.; FUKUSHI, K.; RABAEY, K.; ROZENDAL, R.A.; YAMAMOTO, K. (2011) Redistribution of wastewater alkalinity with a microbial fuel cell to support nitrification of reject water. Water research, v. 45, p. Z 2691-2699.

MORGAN-SAGASTUME, J.M.; NOYOLA, A. (2008) Evaluation of an aerobic submerged filter packed with volcanic scoria. Bioresource Technology, v. 99, p. 2528-2536.

QIU, L.; ZHANG, S.; WANG, G.; DU, M. (2010) Performances and nitrification properties of biological aerated filters with zeolite, ceramic particle and carbonate media. Bioresource Technology, v. 101, p. 72457251.

SENGUPTA, S.; ERGAS, S.; LOPEZ-LUNA, E.; SAHU, A.K.; PALANISWAMY, K. (2006) Autotrophic biological denitrification for complete removal of nitrogen from septic system wastewater. Water, Air and Soil Pollution, v. 6, p. 111-126.

VOGEL, A.L. (1981) Análise inorgânica qualitativa. 4 ed. Rio de Janeiro: Guanabara, $660 \mathrm{p}$.

XIE, W.; WANG, Q.; SONG, G.; KONDO, M.; TERAOKA, M.; OHSUMI, Y.; OGAWA, H.I. (2004) Upflow biological filtrating with floating filter media. Process Biochemistry, v. 39, p. 765-770.

YU, Y.; FENG, Y.; QIU, L.; HAN, W.; GUAN, L. (2008) Effect of grainslag media for the treatment of wastewater in a biological aerated filter. Bioresource Technology, v. 99, p. 4120-4123 